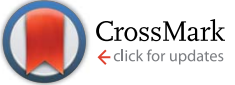

Cite this: J. Mater. Chem. A, 2015, 3, 6276

Received 24th December 2014 Accepted 3rd February 2015

DOI: $10.1039 / c 4 t a 07115 h$

\section{A supermolecular building layer approach for gas separation and storage applications: the eea and rtl MOF platforms for $\mathrm{CO}_{2}$ capture and hydrocarbon separation $\dagger$}

\author{
Zhijie Chen, Karim Adil, Łukasz J. Weseliński, Youssef Belmabkhout \\ and Mohamed Eddaoudi*
}

www.rsc.org/MaterialsA

\begin{abstract}
The supermolecular building layer (SBL) approach was employed to deliberately synthesize five novel metal-organic frameworks (1-5) with an exposed array of amide or amine functionalities within their pore system. The ability to decorate the pores with nitrogen donor moieties offers potential to evaluate/elucidate the structure-adsorption property relationship. Two MOF platforms, eea-MOF and rtl-MOF, based on pillaring of kgm-a or sql-a layers with heterofunctional 3connected organic building blocks were targeted and constructed to purposely introduce and expose the desired amide or amine functionalities. Interestingly, gas adsorption properties of eea-MOF-4 (1) and eea-MOF-5 (2) showed that by simply altering the nitrogen donor position within the ligand, it is possible to relatively reduce the pore size of the related eea-MOF material and subsequently increase the associated $\mathrm{CO}_{2}$ uptake. The slightly confined pore space in 2 , relative to 1 , has enabled an enhancement of the pore local charge density and thus the observed relative increase in the $\mathrm{CO}_{2}$ and $\mathrm{H}_{2}$ isosteric heat of adsorption $\left(Q_{\mathrm{st}}\right)$. In addition, light hydrocarbon adsorption studies revealed that 2 is more selective toward $\mathrm{C}_{2} \mathrm{H}_{6}$ and $\mathrm{C}_{3} \mathrm{H}_{8}$ over $\mathrm{CH}_{4}$ than 1, as exemplified for $\mathrm{C}_{2} \mathrm{H}_{6}: \mathrm{CH}_{4}(5: 95)$ or $\mathrm{C}_{3} \mathrm{H}_{8}: \mathrm{CH}_{4}(5: 95)$ binary gas mixtures.
\end{abstract}

\section{Introduction}

In recent years, metal-organic frameworks (MOFs) have emerged as an attractive class of solid-state materials owing to their associated exceptional wide range of properties pertinent

Functional Materials Design, Discovery and Development Research Group $\left(F M D^{3}\right)$, Advanced Membranes and Porous Materials Center (AMPM), Division of Physical Sciences and Engineering, King Abdullah University of Science and Technology (KAUST), Thuwal 23955-6900, Kingdom of Saudi Arabia. E-mail: mohamed. eddaoudi@kaust.edu.sa

$\dagger$ Electronic supplementary information (ESI) available: Materials and methods, synthesis of ligands, NMR spectra, synthesis of MOFs, additional structural figures, PXRD, TGA, low and high pressure gas adsorption isotherms, $Q_{\mathrm{st}}$ analysis and IAST calculations, Crystallographic Information Files (CIF). CCDC 1036004-1036007 and 1044642. For ESI and crystallographic data in CIF or other electronic format see DOI: $10.1039 / \mathrm{c} 4 \mathrm{ta} 07115 \mathrm{~h}$ to gas storage/separation, ${ }^{\mathbf{1 - 7}}$ catalysis, ${ }^{\mathbf{8}}$ surface chemistry and sensors $^{9,10}$ and drug controlled release. ${ }^{11-13}$ Importantly, advances in MOF crystal chemistry offer potential to ideally practice the building block approach based-assembly for the construction of a given MOF with desired and appropriate chemical and structural features for specific applications. ${ }^{\mathbf{1 4}}$ Namely, the ability to design and construct a MOF with the appropriate pore size, shape and functionality offers prospects to rationally correlate properties with the structure, and subsequently access appropriate MOF platforms ${ }^{15}$ that can address some difficult and energy intensive gas separations, e.g. $\mathrm{CO}_{2}$ capture ${ }^{16,17}$ and hydrocarbon separation. ${ }^{18,19}$ Nevertheless, the unequivocal prediction of a given MOF structure prior to its assembly remains an ongoing challenge; our group has recently published an elaborate tutorial review highlighting distinct strategies that can assist/aid chemists to rationally assemble desired functional MOFs. ${ }^{20}$

A unique and powerful assembly strategy, detailed in the aforementioned review, is based on the use of pre-targeted 2periodic MOF layers as supermolecular building layers (SBLs) for the deliberate construction of 3-periodic functional MOFs. ${ }^{20}$ In the present study, we employed the SBL approach to deliberately synthesize functional MOFs with an exposed array of amide or amine functionalities within their pore system. Specifically, two MOF platforms based on $(3,6)$-connected nets with eea and rtl underlying topologies were targeted, i.e. eeaMOF and rtl-MOF platforms. ${ }^{21-24}$ The elected two MOF platforms consist of inter-connected layers and thus can be regarded as 3-periodic MOFs based on pillared 2-periodic SBLs. ${ }^{20}$ Indeed, our research group has employed successfully the SBL approach to target and construct isoreticular tbo-MOFs, ${ }^{25}$ exhibiting large surface areas and exceptional $\mathrm{CH}_{4}$ storage working capacity for stationary applications. ${ }^{18}$ Similarly, other 3-periodic porous MOFs can be potentially targeted via pillaring SBLs based on one of the sole five edge-transitive 2-periodic nets: sql (square lattice), kgm (Kagomé), hcb (honeycomb), kgd (Kagomé dual) and hex (hexagonal lattice). ${ }^{15}$ Noticeably, augmenting the aforementioned nets, i.e. replacing a vertex with a 
vertex figure, reveals only two distinct possibilities for the assembly of squares into edge-transitive 2-periodic nets, namely sql-a and kgm-a.

The distinctive kgm-a and sql-a nets can be regarded as ideal blueprints to target 2-periodic MOFs based on the assembly of square building units, derived from well-known metal paddlewheel clusters as molecular building blocks (MBBs). ${ }^{26}$ Subsequently, the resultant MOF layers can be perceived as SBLs that are amenable to pillaring through 2-, 3-, 4- or 6-connected organic building blocks for the construction of desired 3-periodic MOF platforms. ${ }^{20}$

Here, the ligand-to-axial (L-A) pillaring strategy, successfully introduced by $\mathrm{us}^{21}$ and demonstrated by others, ${ }^{23,24}$ has been employed to introduce the desired functionality into the resultant MOF via pillar moieties. Purposely, triangular heterofunctional ligands were conceived to contain concurrently (i) the isophthalic moiety, needed for the formation of the layers in combination with dinuclear cluster paddlewheel MBBs, (ii) nitrogen donor moiety necessary for connecting neighboring layers via its coordination to an apical position in the dinuclear cluster, and (iii) specific functional groups such as acetylamide $^{27-30}$ or amines ${ }^{31,32}$ that offer potential to enhance the affinity between $\mathrm{CO}_{2}$ molecules and the pore system in the resultant (3,6)-connected 3-periodic MOF.

Indeed, 3-connected organic building blocks (5-R-isophthalic acid with $\mathrm{R}=$ isonicotinamido, nicotinamido, pyridin4-ylamino, pyridin-3-ylamino, and pyrimidin-5-ylamino) were synthesized and employed in combination with the dinuclear copper paddlewheel to yield the targeted eea-MOF-4 (1), eeaMOF-5 (2), rtl-MOF-2 (3), rtl-MOF-3 (4) and rtl-MOF-4 (5). Interestingly, gas adsorption properties of eea-MOF-4 (1) and eea-MOF-5 (2) showed that by simply altering the nitrogen donor position within the ligand, it is possible to relatively reduce the pore size of the related eea-MOF material and subsequently increase the associated $\mathrm{CO}_{2}$ uptake and relative affinity toward light hydrocarbons.

\section{Results and discussion}

The solvothermal reaction of copper nitrate and 5-(isonicotinamido)isophthalic acid $\left(\mathrm{H}_{2} \mathrm{~L} 1\right)$ in $N, N^{\prime}$-dimethylacetamide (DMA)/acetic acid (HOAc) at $115{ }^{\circ} \mathrm{C}$ for $24 \mathrm{~h}$ yielded green block microcrystals. The structure of the as-synthesized compound was determined by single-crystal X-ray diffraction (SCXRD) and formulated as $\mathrm{Cu}(\mathrm{L} 1) \cdot(\text { solv })_{x}$ (1), eea-MOF-4 (Fig. 1). The phase purity of the crystalline material was confirmed by similarities between the experimental and calculated powder X-ray diffraction (PXRD) patterns (ESI, Fig. S9†).

The resultant 3-periodic eea-MOF-4 can be regarded as kgmMOF layers interconnected via an L-A pillaring approach, where L1 serves as a 3-connected node and the paddlewheel MBB as a 6-connected octahedral building unit. Topological analysis reveals that 1 has the anticipated eea underlying net topology (ESI, Fig. S7†). It is worth noting that while writing the present manuscript, a similar compound appeared in the literature. ${ }^{30}$

The kgm-MOF sheets in $\mathbf{1}$ are pillared in an arrangement where pairs of three-membered ring windows of neighboring

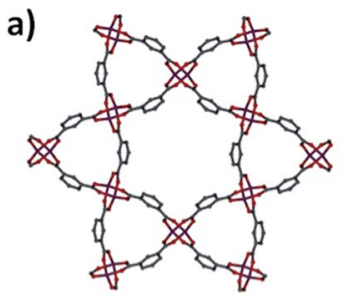

b)

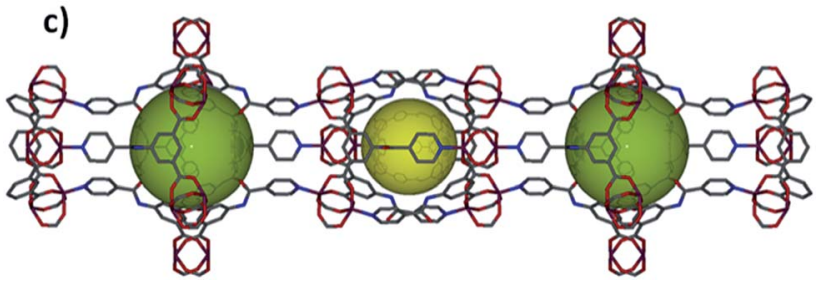

Fig. 1 (a) Layer segment of a kgm-MOF. (b) Left: 5-(isonicotinamido) isophthalic acid $\left(\mathrm{H}_{2} \mathrm{~L} 1\right)$ and right: 5-(nicotinamido)isophthalic acid $\left(\mathrm{H}_{2} \mathrm{~L} 2\right)$. (c) Hourglass-shaped channels with two primary types of cavities. $\mathrm{C}=$ gray, $\mathrm{O}=$ red, $\mathrm{N}=$ blue, $\mathrm{Cu}=$ plum; $\mathrm{H}$ atoms are omitted for clarity.

sheets are further interconnected via interfacing six-membered ring windows (i.e., 3, 3, 6, 3, 3) to yield hourglass-shaped channels (Fig. 1c). These hourglass-shaped channels are comprised of two alternating kinds of cavities (7.8 A and $10.5 \AA$ diameters), one is delimited by neighboring three membered rings and the second is generated from enclosing hexagonal windows by two three-membered ring windows from the two neighboring layers, as shown in Fig. 1. The calculated total accessible volume for the as-synthesized 1, upon removal of guest solvent molecules, was estimated to be $6887 \AA^{3}$ per unit cell volume (11558 $\AA^{3}$ ) or $59.6 \% \mathrm{v} / \mathrm{v}$.

The eea-MOF platform offers potential to control and finetune the pore size via shifting the $\mathrm{N}$-donor group of the pyridine rings within the 3-connected organic building block. Accordingly, we synthesized and used 5-(nicotinamido)isophthalic acid $\left(\mathrm{H}_{2} \mathrm{~L} 2\right)$ under similar reaction conditions to construct the anticipated isoreticular eea-MOF-5 (2). The single-crystal analysis confirms the expected crystal structure formulated as $\mathrm{Cu}(\mathrm{L} 2) \cdot(\text { solv })_{x}$ (Fig. 1). The replacement of isonicotinamide by the nicotinamide group resulted in slight changes in the size and shape of the two cavities (7.6 ̊ and 9.8 $\AA$ diameters).

The experimental PXRD of the bulk material matches perfectly the calculated PXRD pattern based on the crystal structure of 2 , confirming the phase purity of the resultant assynthesized 2 (ESI, Fig. S9†). The thermogravimetric analysis (TGA) of compounds 1 and 2 reveals the stability of compounds 1 and 2 up to $523 \mathrm{~K}$ (ESI, Fig. S11†).

In order to confirm the versatility of the SBL approach for the synthesis of isoreticular MOFs, we synthesized three additional 3-connected organic building blocks (5-R-isophthalic acid with $\mathrm{R}=$ pyridin-4-ylamino, pyridin-3-ylamino, and pyrimidin-5-ylamino). The reaction between copper nitrate and 5-(pyridin-4ylamino)isophthalic acid $\left(\mathrm{H}_{2} \mathrm{~L} 3\right)$ in a mixture of $N, N^{\prime}$-dimethylformamide (DMF), ethanol and water resulted in a 3-periodic $\mathrm{MOF}, \mathrm{Cu}(\mathrm{L} 3) \cdot(\operatorname{solv})_{x}, 3$, based on a triangular organic building block interconnecting 2-periodic sql-MOF layers in a ligand-to- 
axial (L-A) pillaring fashion (Fig. 2). Topological analysis reveals that 3 is consistent with the anticipated rtl topology, where L3 serves as a 3-connected node and the paddlewheel MBB as a 6connected node (ESI, Fig. S8†).

The sql-a MOF layer comprises square windows where a pair of adjacent benzene moieties in any given four-membered ring points up while the other adjacent pair points down, i.e. benzene moieties in the four-membered ring are arranged in a 1,2-alternate fashion. The quadrangular windows of neighboring 2D sql MOF layers are superimposed to generate channels $(2.9 \times 7.1 \AA)$ running along the $c$-axis. The calculated total accessible volume for the as-synthesized 3, upon removal of guest solvent molecules, was estimated to be $3216 \AA^{3}$ per unit cell volume $\left(6203 \AA^{3}\right)$ or $51.9 \% \mathrm{v} / \mathrm{v}$.

As expected, the reaction between copper nitrate and 5-(pyridin-3-ylamino)isophthalic acid $\left(\mathrm{H}_{2} \mathrm{~L} 4\right)$, or 5-(pyrimidin-5ylamino)isophthalic acid $\left(\mathrm{H}_{2} \mathrm{~L} 5\right)$ yielded the formation of two isoreticular rtl-MOF materials as a result of L-A pillaring of sql-a MOF layers, $\mathrm{Cu}(\mathrm{L} 4) \cdot(\mathrm{solv})_{x}$ and $\mathrm{Cu}(\mathrm{L} 5) \cdot(\mathrm{solv})_{x}$, respectively (Fig. 2). Similar to eea-MOF-4 and eea-MOF-5, the use of different isomers/analogs resulted in slight changes in the associated channel size dimensions $(3.55 \times 5.6 \AA)$.

The experimental PXRD of the as-synthesized bulk materials matches perfectly the respective calculated PXRD pattern based on the associated crystal structure, confirming the phase purity of the resultant as-synthesized 3-5 (ESI, Fig. S10 $\dagger$ ).

The permanent porosity of $\mathbf{1}$ and $\mathbf{2}$ has been confirmed by argon (Ar) adsorption isotherms at $87 \mathrm{~K}$ (Fig. 3). Ar adsorption experiments on compound $\mathbf{1}$ show a fully reversible type-I isotherm, characteristic of a microporous material with permanent microporosity. The apparent Langmuir surface area of 1 was estimated to be $1860 \mathrm{~m}^{2} \mathrm{~g}^{-1}$ and the experimental total pore volume derived from the Ar isotherm was found to be

a)

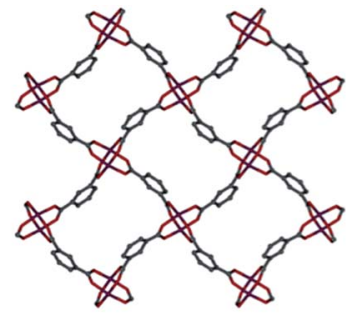

b)
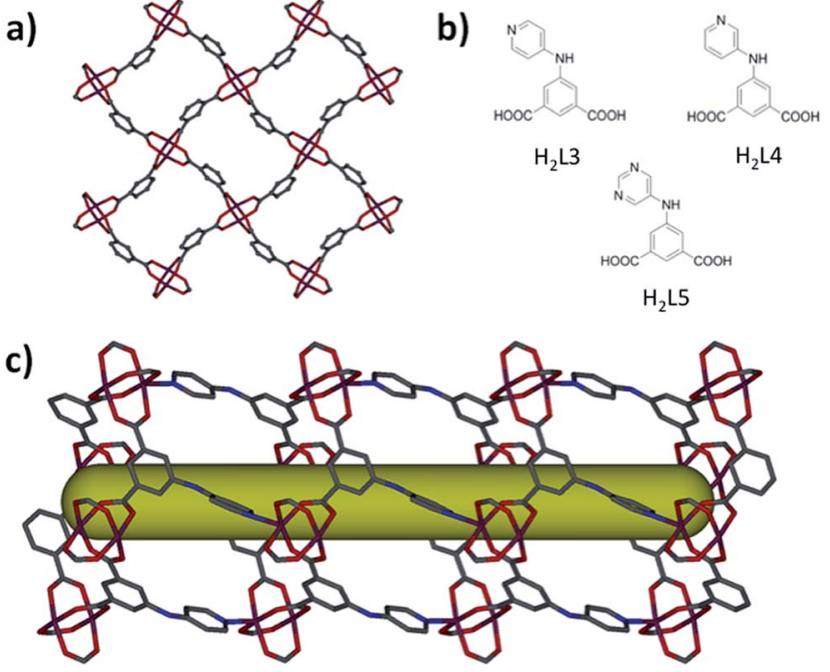

Fig. 2 (a) Layer segment of a sql-MOF. (b) Left, up: 5-(pyridin-4-ylamino)isophthalic acid $\left(\mathrm{H}_{2} \mathrm{~L} 3\right)$. Right, up: 5-(pyridin-3-ylamino)isophthalic acid $\left(\mathrm{H}_{2} \mathrm{~L} 4\right)$. Bottom: 5-(pyrimidin-5-ylamino)isophthalic acid $\left(\mathrm{H}_{2} \mathrm{~L} 5\right)$. (c) Projection along the a-axis of the rtl-MOF-2 displaying channel. $\mathrm{C}=$ gray, $\mathrm{O}=$ red, $\mathrm{N}=$ blue, and $\mathrm{Cu}=$ plum; $\mathrm{H}$ atoms are omitted for clarity.

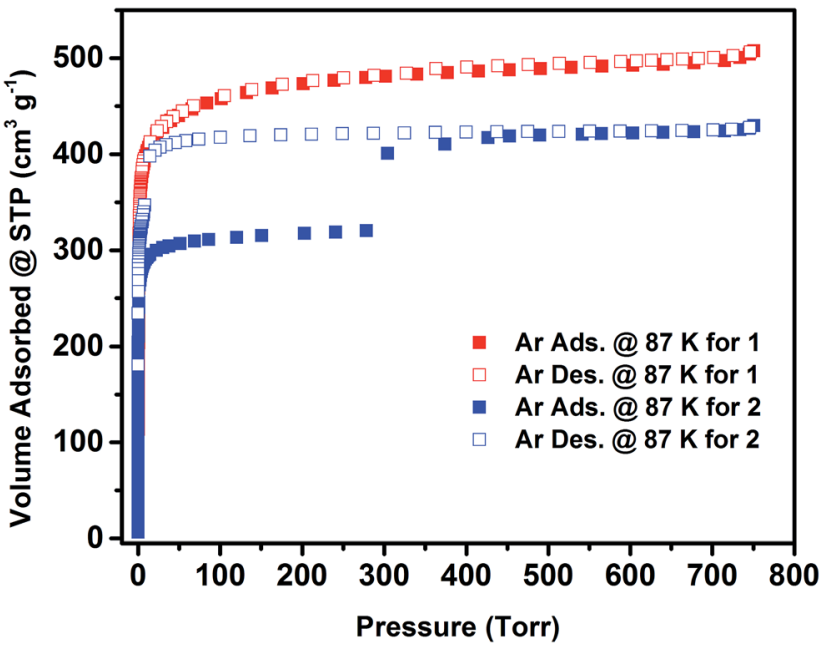

Fig. 3 Low pressure argon adsorption (solid squares) and desorption (open squares) isotherms at $87 \mathrm{~K}$ for the acetone exchanged 1 and 2 .

$0.65 \mathrm{~cm}^{3} \mathrm{~g}^{-1}$, which is in good agreement with the calculated pore volume from the crystal structure $\left(0.66 \mathrm{~cm}^{3} \mathrm{~g}^{-1}\right)$. In contrast, 2 displayed an unusual two-step adsorption isotherm with stepwise adsorption behaviour and a noticeable wide-open hysteresis, which can be symptomatic of plausible framework flexibility. The amount of argon adsorbed up to the first plateau was estimated to be $\sim 320 \mathrm{~cm}^{3} \mathrm{~g}^{-1}$, and the total amount of argon adsorbed in the framework was estimated to be $\sim 430 \mathrm{~cm}^{3}$ $\mathrm{g}^{-1}$, equivalent to an uptake increase of nearly $\sim 110 \mathrm{~cm}^{3} \mathrm{~g}^{-1}$ between the two adsorption plateaus. Accordingly, the apparent Langmuir surface area of compound 2, determined using the adsorption data leading to the first plateau, was estimated to be $1200 \mathrm{~m}^{2} \mathrm{~g}^{-1}$. The estimated total pore volume of 2 derived from the Ar isotherm was estimated to be $0.54 \mathrm{~cm}^{3} \mathrm{~g}^{-1}$, matching the total uptake at the second plateau, and correlates remarkably with the calculated total pore volume from the crystal structure $\left(0.52 \mathrm{~cm}^{3} \mathrm{~g}^{-1}\right)$. Notably, the total pore volume of $2\left(0.54 \mathrm{~cm}^{3} \mathrm{~g}^{-1}\right)$ is smaller than the total volume of $\mathbf{1}\left(0.66 \mathrm{~cm}^{3} \mathrm{~g}^{-1}\right)$, confirming the contraction of the pore system in 2 as a result of nitrogen position in the pillaring ligand.

The shapes of the Ar adsorption/desorption isotherms at cryogenic temperature suggest a plausible gate effect occurring around $14 \mathrm{mmol} \mathrm{g}^{-1}$ of adsorbed $\mathrm{Ar}$ at $87 \mathrm{~K}$. In order to verify the occurrence of this adsorption gate effect, we explored the adsorption of different other probe molecules, namely $\mathrm{CO}_{2}$, $\mathrm{C}_{3} \mathrm{H}_{8}$ and $n-\mathrm{C}_{4} \mathrm{H}_{10}$. Markedly, the aforementioned adsorption gate effect was also observed with these probe molecules at relatively low and high pressures (ESI, Fig. S14-S18 $\dagger$ ).

Interestingly, the adsorbed amounts corresponding to the first plateau were reduced from $\mathrm{CO}_{2}\left(7 \mathrm{mmol} \mathrm{g}{ }^{-1}\right), \mathrm{C}_{3} \mathrm{H}_{8}$ $\left(4.2 \mathrm{mmol} \mathrm{g}^{-1}\right)$ to $n-\mathrm{C}_{4} \mathrm{H}_{10}\left(3.75 \mathrm{mmol} \mathrm{g}^{-1}\right)$ in accordance with the increase in the sorbate kinetic diameter and polarizability (ESI, Fig. S19†).

In order to further explore the MOF associated adsorption properties, $\mathrm{CO}_{2}, \mathrm{H}_{2}, \mathrm{~N}_{2}$, and light hydrocarbon adsorption experiments were carried out at various temperatures and pressures. The $\mathrm{CO}_{2}$ adsorption uptake (298 K) of 1 at 0.15 and 1 
bar was $0.56 \mathrm{mmol} \mathrm{g}^{-1}$ and $3 \mathrm{mmol} \mathrm{g}^{-1}$, respectively (Fig. 4). By contracting the pore size, the $\mathrm{CO}_{2}$ adsorption uptake (298 K) of 2 at 0.15 and 1 bar increased by $67 \%\left(0.94 \mathrm{mmol} \mathrm{g}^{-1}\right)$ and $50 \%$ $\left(4.5 \mathrm{mmol} \mathrm{g}^{-1}\right)$, respectively. The $\mathrm{CO}_{2}$ adsorption uptake of 2 at 1 bar and $298 \mathrm{~K}$ is higher than most of the acylamide functional MOFs. ${ }^{29}$ In contrast to the increased uptake of $\mathrm{CO}_{2}, 2$ shows similar uptake of methane and nitrogen at $298 \mathrm{~K}$ to 1 , which can only adsorb limited amounts of $\mathrm{CH}_{4}\left(0.9 \mathrm{mmol} \mathrm{g}^{-1}\right)$ and $\mathrm{N}_{2}$ $\left(0.18 \mathrm{mmol} \mathrm{g}^{-1}\right)$ at $298 \mathrm{~K}$ and 1 bar. Ideal adsorbed solution theory (IAST) ${ }^{33}$ was used to predict the separation factor of equimolar $\mathrm{CO}_{2} / \mathrm{CH}_{4}$ and $\mathrm{CO}_{2} / \mathrm{N}_{2}$ (10:90) mixtures using experimentally obtained single gas adsorption isotherms (Fig. 5).

IAST selectivity prediction is a valid methodology when the same elaborate model fits matchlessly the experimental data from single gas adsorption isotherms. ${ }^{34}$ Accordingly, IAST can be confidently used to evaluate gas selectivities in eea-MOFs. Compared with 1 , the predicted separation factors of $\mathrm{CO}_{2} / \mathrm{N}_{2}$ and $\mathrm{CO}_{2} / \mathrm{CH}_{4}$ for 2 are significantly improved from 19.2 to 39.3 and from 4.3 to 7.3 , respectively. To better understand the energetics of the interaction between $\mathrm{CO}_{2}$ and associated MOFs, the isosteric heat of adsorption $\left(Q_{\mathrm{st}}\right)$ over the entire studied range was calculated for 1 and 2 using $\mathrm{CO}_{2}$ isotherms at 258, 273, 288 and $298 \mathrm{~K}$ (ESI, Fig. S14 and S15 $\dagger$ ). The $Q_{\text {st }}$ of $\mathrm{CO}_{2}$ adsorption for $\mathbf{2}$ is slightly higher than $\mathbf{1}$ over the whole range, with the highest point at ca. 27.5 over ca. $24.6 \mathrm{~kJ} \mathrm{~mol}^{-1}$ (Fig. 4, inset). The $Q_{\text {st }}$ of $\mathrm{CO}_{2}$ adsorption for 2 is relatively high among MOFs without open metal sites. ${ }^{35}$ Clearly, the confined space promoted relatively favorable interactions (high localized charge density) between the $\mathrm{CO}_{2}$ and the framework and subsequently improved the $\mathrm{CO}_{2}$ adsorption energetics and uptake. $^{36}$

With regard to hydrogen adsorption, $Q_{\text {st }}$ of 2 was found to be higher than 1 over the entire adsorption range (e.g., 7.15 vs. 6.15 $\mathrm{kJ} \mathrm{mol}^{-1}$ at low loading); nevertheless, the uptake at $77 \mathrm{~K}$ and 1 bar was comparable for 1 and 2 (1.96 vs. 1.98 wt\%) (ESI, Fig. S12 and S13 $\dagger$ ). In this case, the observed increase in the $\mathrm{H}_{2}$

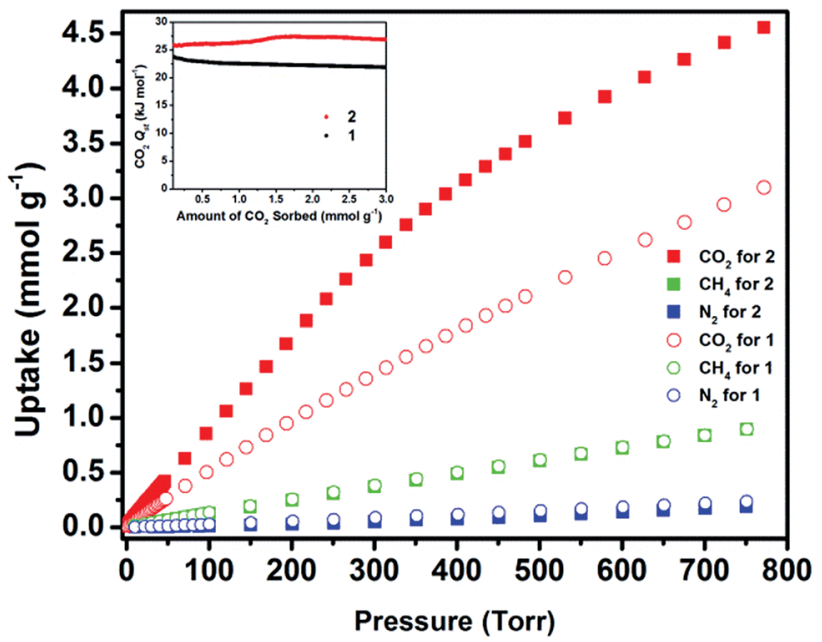

Fig. 4 Single component gas adsorption isotherms for $\mathrm{CO}_{2}, \mathrm{CH}_{4}$ and $\mathrm{N}_{2}$ at $298 \mathrm{~K}$ and $\mathrm{CO}_{2} Q_{\mathrm{st}}$ (inset) for 1 and 2 .

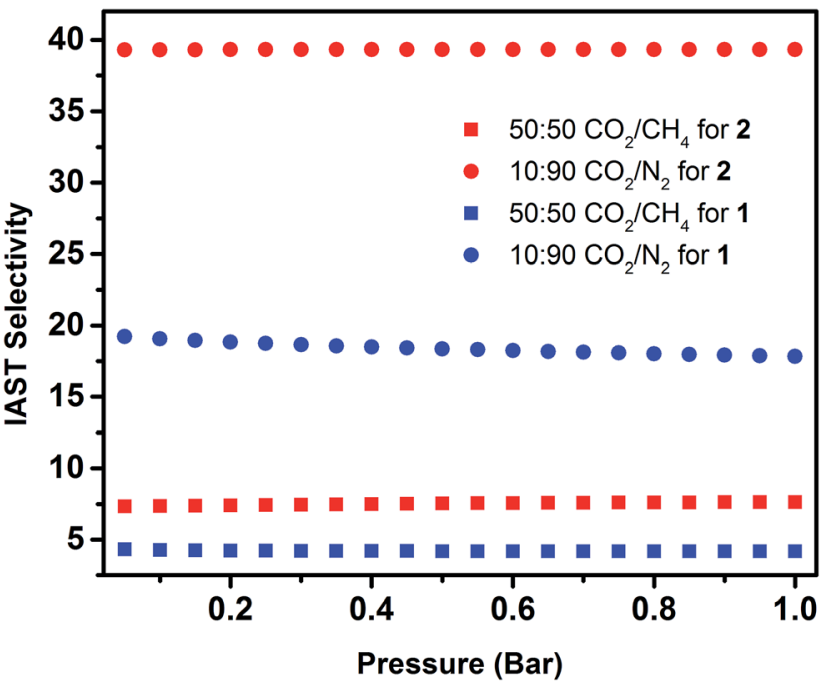

Fig. 5 IAST selectivities for $50: 50 \mathrm{CO}_{2} / \mathrm{CH}_{4}$ (squares) and $10: 90$ $\mathrm{CO}_{2} / \mathrm{N}_{2}$ (circles) binary mixtures predicted at $298 \mathrm{~K}$ for 1 (blue) and 2 (red).

adsorption energetics for 2 can be interpreted as a result of the confined space effect, promoting a higher localized charge density in a more comparatively confined space. ${ }^{37}$

Adsorption studies of $\mathrm{CH}_{4}, \mathrm{C}_{2} \mathrm{H}_{6}$ and $\mathrm{C}_{3} \mathrm{H}_{8}$ were conducted in order to evaluate $\mathbf{1}$ and $\mathbf{2}$ separation potential of light hydrocarbons.

The $\mathrm{C}_{2} \mathrm{H}_{6}$ and $\mathrm{C}_{3} \mathrm{H}_{8}$ adsorption uptake for $\mathbf{1}$ at 1 bar and 298 $\mathrm{K}$ is 5.21 and $5.99 \mathrm{mmol} \mathrm{g}^{-1}$, which are higher than the $\mathrm{C}_{2} \mathrm{H}_{6}$ and $\mathrm{C}_{3} \mathrm{H}_{8}$ uptake for 2 (4.31 and $4.77 \mathrm{mmol} \mathrm{g}^{-1}$, respectively) (Fig. 6). This observed enhanced hydrocarbon adsorption uptake for $\mathbf{1}$ can be attributed to a comparatively larger available total pore volume in 1 relative to 2 . Nevertheless, the predicted adsorption separation factors (using IAST) of $\mathbf{1}$ and 2 for $\mathrm{C}_{2} \mathrm{H}_{6}$ and $\mathrm{C}_{3} \mathrm{H}_{8}$ over $\mathrm{CH}_{4}$ in $5: 95 \mathrm{C}_{2} \mathrm{H}_{6} / \mathrm{CH}_{4}$ and $5: 95 \mathrm{C}_{3} \mathrm{H}_{8} / \mathrm{CH}_{4}$ binary gas mixtures reveal a slightly higher selectivity for 2

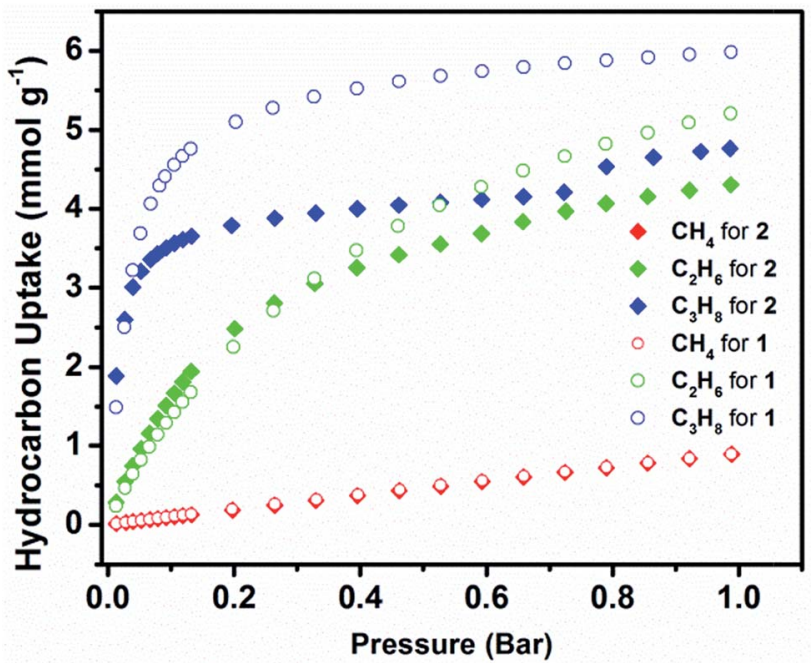

Fig. 6 Single component gas adsorption isotherms for $\mathrm{C}_{3} \mathrm{H}_{8}, \mathrm{C}_{2} \mathrm{H}_{6}$ and $\mathrm{CH}_{4}$ at $298 \mathrm{~K}$ for 1 and 2 . 


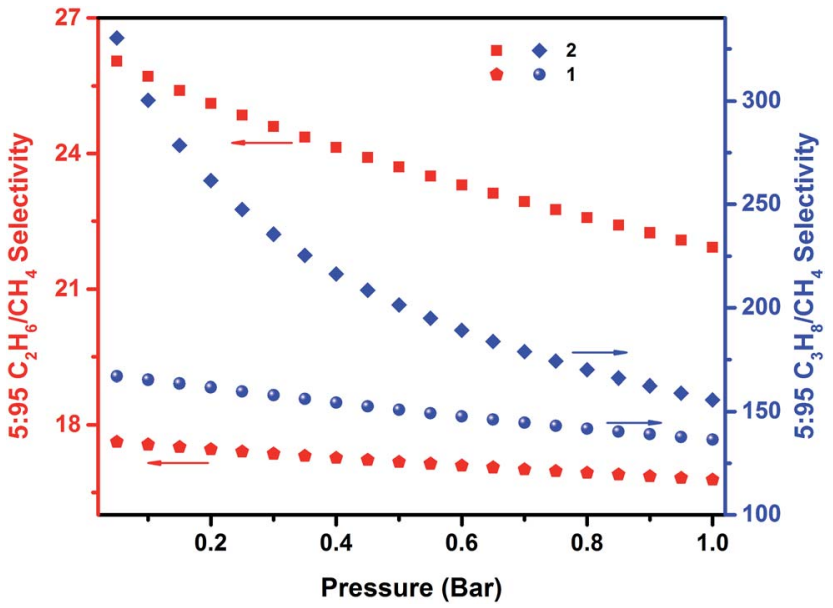

Fig. 7 IAST selectivities for $5: 95 \mathrm{C}_{2} \mathrm{H}_{6} / \mathrm{CH}_{4}$ (red; left ordinate) and $5: 95 \mathrm{C}_{3} \mathrm{H}_{8} / \mathrm{CH}_{4}$ (blue; right ordinate) binary mixtures predicted at 298 $\mathrm{K}$ for 1 and 2 .

(156 and 22, respectively) than 1 (136 and 17, respectively) at 298 $\mathrm{K}$ and 1 bar (Fig. 7). These results support, as in the case of the $\mathrm{CO}_{2}$ separation, the impact of pore size reduction on the affinity enhancement for light hydrocarbons versus methane.

\section{Conclusions}

We have successfully utilized the supermolecular building layer (SBL) approach for the design and construction of isoreticular (3,6)-connected eea-MOFs and rtl-MOFs. The acylamide-functionalized eea-MOF showed a relatively good capacity for $\mathrm{CO}_{2}$ storage, as well as good selectivity toward $\mathrm{CO}_{2}$ and $\mathrm{C}_{3} \mathrm{H}_{8}$ at 298 $\mathrm{K}$. The deliberate pore size reduction resulted in an enhanced local charge density and subsequently an increased $\mathrm{CO}_{2}$ uptake at both relatively low pressures $(0.15$ bar $)$ and atmospheric pressures. Light hydrocarbon separation studies suggest that $\mathrm{C}_{2} \mathrm{H}_{6}$ and $\mathrm{C}_{3} \mathrm{H}_{8}$ could be selectively removed from natural gas to produce a relatively valuable commodity such as $\mathrm{CH}_{4}$. This MOF platform, based on the ligand-to-axial (L-A) pillaring approach, offers opportunities to readily functionalize and fine-tune the MOF pores with moieties that can favorably interact with a given probe molecule and subsequently provide access to functional MOF materials with improved attributes for gas separation and storage.

\section{Acknowledgements}

Research reported in this publication was supported by the King Abdullah University of Science and Technology (KAUST).

\section{Notes and references}

1 K. Sumida, D. L. Rogow, J. A. Mason, T. M. McDonald, E. D. Bloch, Z. R. Herm, T.-H. Bae and J. R. Long, Chem. Rev., 2011, 112, 724-781.

2 O. K. Farha, A. O. Yazaydın, I. Eryazici, C. D. Malliakas, B. G. Hauser, M. G. Kanatzidis, S. T. Nguyen, R. Q. Snurr and J. T. Hupp, Nat. Chem., 2010, 2, 944-948.
3 P. Nugent, Y. Belmabkhout, S. D. Burd, A. J. Cairns, R. Luebke, K. Forrest, T. Pham, S. Ma, B. Space, L. Wojtas, M. Eddaoudi and M. J. Zaworotko, Nature, 2013, 495, 80-84.

4 E. D. Bloch, W. L. Queen, R. Krishna, J. M. Zadrozny, C. M. Brown and J. R. Long, Science, 2012, 335, 1606-1610.

5 H. Wu, Q. Gong, D. H. Olson and J. Li, Chem. Rev., 2012, 112, 836-868.

6 Z. Zhang, Z.-Z. Yao, S. Xiang and B. Chen, Energy Environ. Sci., 2014, 7, 2868-2899.

7 Y. Peng, V. Krungleviciute, I. Eryazici, J. T. Hupp, O. K. Farha and T. Yildirim, J. Am. Chem. Soc., 2013, 135, 11887-11894.

8 J. Liu, L. Chen, H. Cui, J. Zhang, L. Zhang and C.-Y. Su, Chem. Soc. Rev., 2014, 43, 6011-6061.

9 S. Qiu, M. Xue and G. Zhu, Chem. Soc. Rev., 2014, 43, 61166140.

10 M. C. So, M. H. Beyzavi, R. Sawhney, O. Shekhah, M. Eddaoudi, S. S. Al-Juaid, J. T. Hupp and O. K. Farha, Chem. Commun., 2015, 51, 85-88.

11 D. Cunha, M. B. Yahia, S. Hall, S. R. Miller, H. Chevreau, E. Elkaïm, G. Maurin, P. Horcajada and C. Serre, Chem. Mater., 2013, 25, 2767-2776.

12 J. An, S. J. Geib and N. L. Rosi, J. Am. Chem. Soc., 2009, 131, 8376-8377.

13 P. Horcajada, R. Gref, T. Baati, P. K. Allan, G. Maurin, P. Couvreur, G. Férey, R. E. Morris and C. Serre, Chem. Rev., 2012, 112, 1232-1268.

14 M. Eddaoudi, D. B. Moler, H. Li, B. Chen, T. M. Reineke, M. O'Keeffe and O. M. Yaghi, Acc. Chem. Res., 2001, 34, 319-330.

15 M. O'Keeffe, M. A. Peskov, S. J. Ramsden and O. M. Yaghi, Acc. Chem. Res., 2008, 41, 1782-1789.

16 O. Shekhah, Y. Belmabkhout, Z. Chen, V. Guillerm, A. Cairns, K. Adil and M. Eddaoudi, Nat. Commun., 2014, 5, 4228.

17 X. Duan, R. Song, J. Yu, H. Wang, Y. Cui, Y. Yang, B. Chen and G. Qian, RSC Adv., 2014, 4, 36419-36424.

18 Y. Belmabkhout, H. Mouttaki, J. F. Eubank, V. Guillerm and M. Eddaoudi, $R S C$ Adv., 2014, 4, 63855-63859.

19 Z. R. Herm, E. D. Bloch and J. R. Long, Chem. Mater., 2014, 26, 323-338.

20 V. Guillerm, D. Kim, J. F. Eubank, R. Luebke, X. Liu, K. Adil, M. S. Lah and M. Eddaoudi, Chem. Soc. Rev., 2014, 43, 61416172.

21 J. F. Eubank, L. Wojtas, M. R. Hight, T. Bousquet, V. C. Kravtsov and M. Eddaoudi, J. Am. Chem. Soc., 2011, 133, 17532-17535.

22 S. Xiang, J. Huang, L. Li, J. Zhang, L. Jiang, X. Kuang and C.-Y. Su, Inorg. Chem., 2011, 50, 1743-1748.

23 X. Liu, M. Oh and M. S. Lah, Inorg. Chem., 2011, 50, 50445053.

24 X. Liu, M. Oh and M. S. Lah, Cryst. Growth Des., 2011, 11, 5064-5071.

25 J. F. Eubank, H. Mouttaki, A. J. Cairns, Y. Belmabkhout, L. Wojtas, R. Luebke, M. Alkordi and M. Eddaoudi, J. Am. Chem. Soc., 2011, 133, 14204-14207.

26 H. Li, M. Eddaoudi, T. L. Groy and O. M. Yaghi, J. Am. Chem. Soc., 1998, 120, 8571-8572. 
27 B. Zheng, H. Liu, Z. Wang, X. Yu, P. Yi and J. Bai, CrystEngComm, 2013, 15, 3517-3520.

28 K. Tang, R. Yun, Z. Lu, L. Du, M. Zhang, Q. Wang and H. Liu, Cryst. Growth Des., 2013, 13, 1382-1385.

29 B. Zheng, J. Bai, J. Duan, L. Wojtas and M. J. Zaworotko, J. Am. Chem. Soc., 2010, 133, 748-751.

30 Y. Xiong, Y.-Z. Fan, R. Yang, S. Chen, M. Pan, J.-J. Jiang and C.-Y. Su, Chem. Commun., 2014, 50, 14631-14634.

31 R. Vaidhyanathan, S. S. Iremonger, K. W. Dawson and G. K. H. Shimizu, Chem. Commun., 2009, 5230-5232.

32 N. Planas, A. L. Dzubak, R. Poloni, L. C. Lin, A. McManus, T. M. McDonald, J. B. Neaton, J. R. Long, B. Smit and L. Gagliardi, J. Am. Chem. Soc., 2013, 135, 7402-7405.
33 A. L. Myers and J. M. Prausnitz, AIChE J., 1965, 11, 121-127. 34 Y. Belmabkhout and A. Sayari, Chem. Eng. Sci., 2009, 64, 3729-3735.

35 S. D. Burd, S. Ma, J. A. Perman, B. J. Sikora, R. Q. Snurr, P. K. Thallapally, J. Tian, L. Wojtas and M. J. Zaworotko, J. Am. Chem. Soc., 2012, 134, 3663-3666.

36 L. Du, Z. Lu, K. Zheng, J. Wang, X. Zheng, Y. Pan, X. You and J. Bai, J. Am. Chem. Soc., 2012, 135, 562-565.

37 Y. Liu, J. F. Eubank, A. J. Cairns, J. Eckert, V. C. Kravtsov, R. Luebke and M. Eddaoudi, Angew. Chem., Int. Ed., 2007, 46, 3278-3283. 